\title{
E-Learning and Semantic Web
}

\author{
Ahmed Rashad Khalifa \\ Systems and Computers Engineering Dept., Faculty of Engineering, Al Azhar University, Cairo, Egypt
}

\section{Email address:}

khalifah2@hotmail.com

\section{To cite this article:}

Ahmed Rashad Khalifa. E-Learning and Semantic Web. International Journal of Intelligent Information Systems.

Vol. 4, No. 5, 2015, pp. 84-94. doi: 10.11648/j.jiiis.20150405.11

\begin{abstract}
Nowadays, e-learning systems are widely used for education and training in universities and companies because of their electronic course content access and virtual classroom participation. But not all learners learn in the same way and at the same rate, some prefer the traditional text-based or oral presentation of content, while others learn more easily in a visual or kinetic instruction style. The real value of e-Learning lies not in its ability to train just anyone, anytime, anywhere, but in our ability to deploy this attribute to train the right people to gain the right skills or knowledge at the right time. Learning objects and courses databases are syntactically structured text archives with powerful search engines. But, there is no semantic relationship between information needs of the user and the information content of documents. Because of many limitations using web 2.0 for creating E-learning management system, now-a-days we use Web 3.0 which is known as Semantic web. It is a platform to represent E-learning management system that recovers the limitations of Web 2.0. However, with the rapid increase of learning content on the Web, it is time-consuming for learners to find contents they really want to and need to study. "Making content machine-understandable" is a popular paraphrase of the fundamental prerequisite for the Semantic Web. This paper focuses on e-Learning, benefits and requirements of e-Learning and potential uses of semantic web technology in e-Learning.
\end{abstract}

Keywords: E-Learning, Semantic Web, RDF, Ontology

\section{Introduction}

The real value of e-Learning lies not in its ability to train just anyone, anytime, anywhere, but in our ability to deploy this attribute to train the right people to gain the right skills or knowledge at the right time [1].

E-learning is not just concerned with providing easy access to learning resources, anytime, anywhere, via a repository of learning resources, but is also concerned with supporting such features as the personal definition of learning goals, and the synchronous and asynchronous communication, and collaboration, between learners and between learners and instructors.

Not all learners learn in the same way and at the same rate. Learners' learning styles that reflect their cognitive abilities vary in known ways; some prefer the traditional text-based or oral presentation of content, while others learn more easily in a visual or kinetic instruction style. Simulation has been shown to be an effective way of teaching abstract concept, principle and process in many application domains.

Web-based e-learning systems are normally used by a wide variety of learners with different skills, background, preferences, and learning styles. Recent advances in
Web-based and E-learning technology provide a wide range of learning materials and learning objects available to learner.

However, the increase of reachable material confuses a selection decision for most suitable learning objects. A support system based on learner demands, backgrounds, and users' preference is needed to help effectively search preferred materials [2]. The Semantic Web can offer more flexibility in e-learning systems through use of new Semantic Web technologies (SWT). Thus, it may advise a learner with most suitable learning objects

Unfortunately, the Web was built for human consumption, not for machine consumption, although everything on the Web is machine-readable, it is not machine-understandable. We need the Semantic Web to express information in a precise, machine interpretable form, ready for software agents to process, share, and reuse it, as well as to understand what the terms describing the data mean. This would enable web-based applications to interoperate both on the syntactic and semantic level.

One of the hottest topics in recent years in the Artificial Intelligence (AI) community, as well as in the Internet community, is the "Semantic Web". It is an evolving 
extension of the World Wide Web (WWW) in which the semantics of information and services on the web is defined, making it possible for the web to understand and satisfy the requests of people and machines to use the web content." It is about making the Web more understandable by machines. It is also about building an appropriate infrastructure for intelligent agents to run around the Web performing complex actions for their users. Furthermore, Semantic Web is about explicitly declaring the knowledge embedded in many web-based applications, integrating information in an intelligent way, providing semantic-based access to the Internet, and extracting information from texts. Ultimately, Semantic Web is about how to implement reliable, large-scale interoperation of Web services, to make such services computer interpretable, i.e., to create a Web of machine-understandable and interoperable services that intelligent agents can discover, execute, and compose automatically.

Semantic Web (http://www.semanticWeb.org/), it is the new-generation Web that makes it possible to express information in a precise, machine-interpretable form, ready for software agents to process, share, and reuse it, as well as to understand what the terms describing the data mean. It enables Web-based applications to interoperate both on the syntactic and semantic level [3].

Note that it is Tim Berners-Lee (inventor of the WWW, URIs, HTTP, and HTML) himself that pushes the idea of the Semantic Web forward. The father of the Web first envisioned a Semantic Web that provides automated information access based on machine-processable semantics of data and heuristics that use these metadata. The explicit representation of the semantics of data, accompanied with domain theories (Ontologies), it enables a Web that provides a qualitatively new level of service, such as: intelligent search engines, information brokers, and information filters. Researchers from the World Wide Web Consortium (W3C) already developed new technologies for web friendly data description. Moreover, AI researchers have already developed some useful applications and tools for the Semantic Web.

We introduce the implementation of Semantic Web concept on the e-Learning environment offered by our web-based E-learning. The facilities that the application will provide include allowing e-learning content to be created, annotated, shared and discussed, together with supplying resources such as lecture notes, course description, documents, announcements, student papers, useful URL links, exercises and quizzes for evaluation of the student knowledge [4].

The major industrial firms and academic and research institutions have started to think seriously about the use and applications of Semantic Web Technology (SWT) in which information in machine processable form can coexist and complement the current web with better enabling computers and people to work in co-operation [5].

This paper is organized as follows: Section (2) presents a brief overview about e-Learning benefits and requirements, section (3) gives a brief overview about the Semantic Web and discusses the common technologies used to construct the Semantic Web as well as the limitations of the conventional Web and how the Semantic Web overcomes those limitations. Section (4) presents an overview about layers of the Semantic Web architecture. In section (5), E-Learning, semantic Web and potential uses of semantic web technology in e-Learning, are discussed. Finally, section (6) concludes the paper.

\section{E-Learning}

Distance Learning is characterized by the fact that the student (learner) does not have to be present in a classroom (a given location) in order to participate in the instruction. Time and place parameters of an instruction can be variable. There is no face-to-face environment.

Although a number of definitions for distance learning (DL) have been proposed over the years, the majority seems to agree on the basic elements, which differentiate the method from conventional teaching and learning. Such elements include separation of the teacher from the learner in space and/or in time during at least a major part of each educational process, the use of special training material to unite teacher and learner and carry course content, the provision of two-way communication between them, and the control of learning by the student [6].

Distance learning can be a good method to transfer and learn new Knowledge and information, the student is a passive learner. Techniques for Distance learning include broadcast TV, audiotape and videotape; it is a one-to-many communication.

An e-learning system can be defined as a social and information technological system that supports learning processes [7].

E-learning is also called Web-based learning, online learning, distributed learning, computer-assisted instruction, or Internet-based learning. Historically, there have been two common e-learning modes: distance learning and computer assisted instruction.

Distance learning uses information technologies to deliver instruction to learners who are at remote locations from a central site.

Computer assisted instruction (also called computer-based learning and computer based training) uses computers to aid in the delivery of stand-alone multimedia packages for learning and teaching. These two modes are subsumed under e-learning as the Internet becomes the integrating technology [8].

E-learning is defined as "The delivery of individualized, comprehensive, dynamic learning content in real time, aiding the development of communities of knowledge, linking learners and practitioners with experts"[9].

Table 1 illustrates the benefits of E-Learning. 
Table 1. Benefits of e-Learning.

\begin{tabular}{|c|c|}
\hline Benefits of e-Learning & \\
\hline $\begin{array}{l}\text { Information is consistent or customised, } \\
\text { depending on need }\end{array}$ & $\begin{array}{l}\text { Everyone gets the same content, presented in the same way. Yet the programs can also be customised for different } \\
\text { learning needs or different groups of people }\end{array}$ \\
\hline Content is more timely and dependable & $\begin{array}{l}\text { Because it is web-enabled, e-Learning can be updated instantaneously, making the information more accurate } \\
\text { and useful for a longer period of time. The ability to upgrade e-Learning content easily and quickly, and then } \\
\text { immediately distribute the new information to users is extremely time efficient. }\end{array}$ \\
\hline Learning is $24 / 7$ & $\begin{array}{l}\text { Students can access e-Learning anywhere and at any time of the } \\
\text { day. It's "just in time - any time' approach makes the learning process ubiquitous. }\end{array}$ \\
\hline Universality & $\begin{array}{l}\text { e-Learning is web-enabled and takes advantage of the universal Internet protocols and browsers. Concern over } \\
\text { differences in platforms and operating systems is rapidly fading. Everyone on the Web can receive virtually the } \\
\text { same material in virtually the same time. }\end{array}$ \\
\hline Scalability & $\begin{array}{l}\text { e-Learning solutions are highly scalable. Programs can move } 10 \text { participants to } 100 \text { or even more participants } \\
\text { with little effort or incremental cost (as long as the infrastructure is in place). }\end{array}$ \\
\hline Builds communities & $\begin{array}{l}\text { The Web enables students to build enduring communities of practice where they can come together to share } \\
\text { knowledge and insight. This can be a tremendous motivator for learning. }\end{array}$ \\
\hline e-Learning lowers costs & $\begin{array}{l}\text { Despite outward appearances, e-Learning is often the most cost effective way to deliver instruction or } \\
\text { information. It cuts travel expenses; it can also reduce teaching time, and significantly reduces the need for a } \\
\text { classroom/teacher infrastructure. }\end{array}$ \\
\hline
\end{tabular}

Drucker [10] has defined e-Learning as "just-in-time education integrated with high velocity value chains. It is the delivery of individualized, comprehensive, dynamic learning content in real time, aiding the development of communities of knowledge, linking learners and practitioners with experts". E-Learning aims at replacing old-fashioned time/place/content/ predetermined learning with a just-in time/ at workplace/customized /on-demand process of learning [11].

Learning environment allows learners to access electronic course contents through the network and study them in virtual classrooms. It brings many benefits in comparison with conventional learning paradigm, e.g. learning can be taken at any time and at any place. However, with the rapid increase of learning content on the Web, it is time-consuming for learners to find contents they really want to and need to study. The challenge in an information-rich world is not only to make information available to people at any time, at any place, and in any form, but to offer the right thing to the right person in the right way [12].

Table 2 shows the characteristics (or pitfalls) of the standard learning scenario and the improvements achieved using the e-learning approach. These are the most important characteristics of e-learning.

Table 2. Difference Between Training and E-Learning [10].

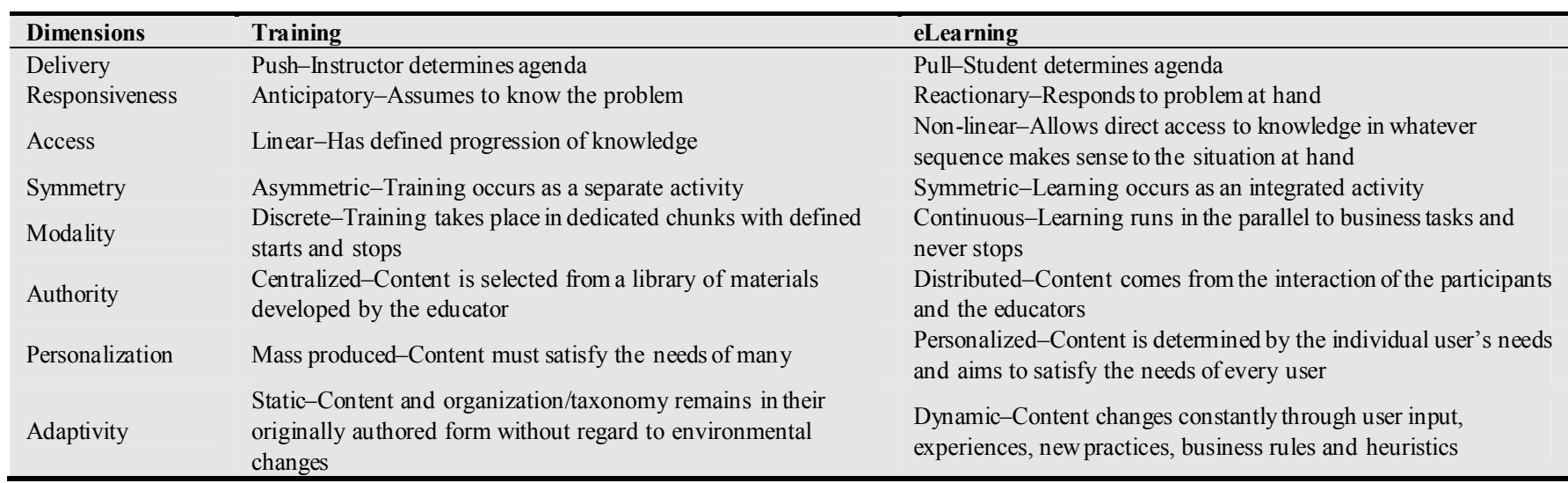

E-Learning and its technological basis: E-Learning environments - proved to be an appropriate tool which can support the learning process efficiently, effectively and satisfactorily. In the future, they will open up to us new dimensions in the world of learning we never experienced before. With their help, the right knowledge will be learnt at the right time, by the right person, in the right context - a lifelong [13]. Courses that never end, provide ongoing digital learning and performance support for the learner, making a number of perpetual courses [14].

Why ('life-long learning')

As mentioned before, there is a growing need for continuing, life-long learning in our society because:

- There is a rapid technological change.

- Training and education is an ongoing necessary in business.

- Workers have to remain current with required skills and knowledge. 
- People change their carriers and jobs more frequently, six to seven changes as average.

- Increasing the skill and knowledge means to increase someone's marketability.

Learning Objectives is defined as the desired outcome of education. Three major learning objectives can be classified (information transfer- Skill Acquisition - Team-learning Experience), which should be taken into consideration when designing a course or a curriculum. It is important to ensure that all parts of skills-cycle have been learned (receive signal, perceive and interpret, decide on action, take action) [15].

The different types of E-learning are based on:

1. Means of communication.

2. Schedule.

3. E-learning class structure.

4. Technologies used.

Not all learners learn in the same way and at the same rate. Learners' learning styles that reflect their cognitive abilities vary in known ways; some prefer the traditional text-based or oral presentation of content, while others learn more easily in a visual or kinetic instruction style. E-Learning has been shown to be an effective way of teaching abstract concept, principle and process in many application domains [16].

Numerous research efforts on the effect of media on learning have shown that different media types have different efficiencies in terms of what a learner can recall. Especially the combination of media has very different efficiencies.

In general from $100 \%$ of the learning material (facts) we can remember, figure 1 illustrates this percentage:

- $10 \%$ through reading,

- $20 \%$ through hearing,

- $30 \%$ through seeing,

- $40 \%$ through hearing and seeing,

- $80 \%$ through hearing, seeing and doing (interacting).

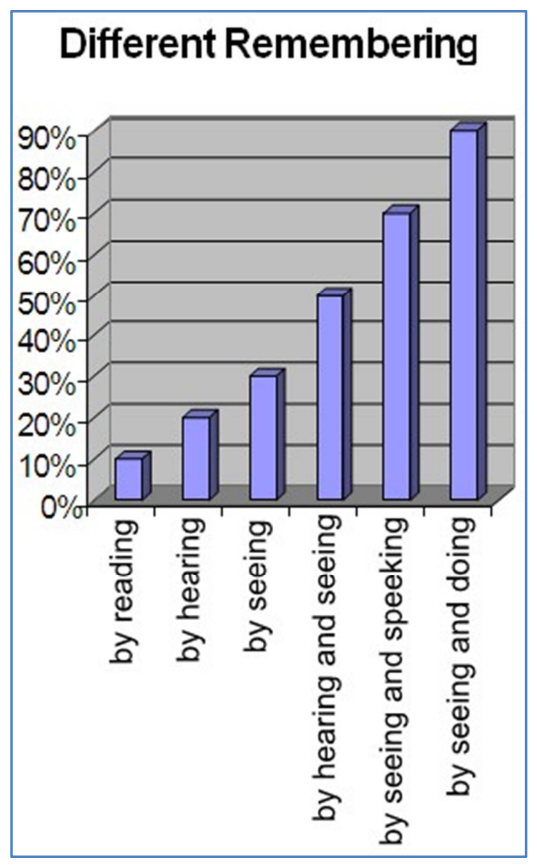

Figure 1. Different Remembering.
In addition to that, well prepared content is fun learning and thus motivates the learner which increases learning success.

To challenge and engage learners, the development team needed to produce courses that offered more than the average page-turner tutorials [17].

\section{Semantic Web}

In the beginning of the internet days, software programmers developed all Web pages. Today, the Web provides perhaps the simplest way to share information, and literally everyone writes Web pages, with the help of authoring tools, and a large number of organizations disseminate data coded in Web pages. The Hypertext Markup Language (HTML) is typically the language used to code information about renderization (font size, color, position on screen, etc.) and hyperlinks to other Webpages or resources on the Web (multimedia files, text, e-mail addresses, etc.).

The net result is that the Web keeps growing at an astounding pace, now having over eight billion Web pages. However, most Web pages are still designed for human consumption and cannot be processed by machines. Computers are used only to display the information. that is, to decode the color schema, headers. and links encoded in Web pages. Furthermore, web search engines, the most popular tools to help retrieve Web pages, do not offer Support to interpret the results. For this reason, human intervention is still required. This situation is progressively getting worse as the size of search results is becoming too large. Most users only browse through the top results, discarding the remaining ones. Some search engines are resorting to artifice to help control the situation, such as indexing the search result, or limiting the search space to a relevant subset of the Web (such as in Google Scholar). The conclusion is that the size of search results is often just too big for humans to interpret, and finding relevant information on the Web is not as easy as we would desire [18].

This traditional or current Web is sometimes called Web 1.0. Since its inception in 1990, the World Wide Web (www) has been visualized as a repository to store information as Web documents. The Web document has been mainly designed in Hyper Text Markup Language (HTML) which enables the document developer to link to other HTML documents. The improvement of technology helps in increasing the number and quality of images, movies and other media elements in the hyper document.

Many search engines are available to search this Web such as Google and Yahoo. These search engines are based on keyword matching. The user enters the keywords to search through the Internet; the search engine returns a list of the pages matching these keywords. The Web pages in the result list may be ranked according to its relevance to the keywords. The browsing, searching, and many other available services on this Web-1 represent "Client Server Model".

A next generation of the Web, called Web 2.0, has been introduced as a social networking where the user contributes to the Web content not just consumes. In Web 2.0, users basically make content of Websites, instead of the Webmasters. 
Wikis, You Tube, and even Twitter are examples of such social Web. The Facebook is another example where users can build social connections with friends. While Web 1.0 has delivered the Internet and connected large numbers of people, Web 2.0 has demonstrated the technology to assemble and manage large global crowds with a common interest in social interaction. Web 2.0 is the current generation of Internet technology. In the context of the social Web, user data is composed of identity, social-graph data identifying the user, and content data. Accessibility to this huge amount of the Web content is still restricted to humans and not to machines and this restricted accessibility causes a lot of problems.

The Semantic Web (Web 3.0) is assumed to be the solution of such problems. It is an extension to the current traditional Web which helps humans and machines to work together and its information has a well defined meaning. In order to allow machines more actions, the Web data must be in a form that machines can understand. This is done by developing new technologies and languages to express the Web data in such forms.

The Semantic Web is the extension of the WWW. That allows people to share content beyond the boundaries of web sites and applications. There are many different ideas about what the Semantic Web is. Berners-Lee, Hendler and Lassila (2001) define the Semantic Web, also known as Web3.0, as "not a separate Web but an extension of the current one, in which information is given well-defined meaning, better enabling computers and people to work in cooperation"[19].

Berners-Lee hopes that eventually computers will be able to use the information on the Web, not just present the information. "Machines become capable of analyzing all the data on the Web. content, links, and transactions between people and computers" [20]. Based on his idea, the Semantic Web is a vision and is considered to be the next step in Web evolution. It is about having data as well as documents on the Web so that machines can process, transform, assemble, and even act on the data in useful ways. One of the great promises of the Semantic Web is flexibility in accessing and identifying information [21].

The Semantic Web is a mesh of information linked up in such a way, as to be easily processable by machines on a global scale. It is the new-generation Web that makes it possible to express information in a precise, machine interpretable form, ready for software agents to process, share, and reuse it, as well as to understand what the terms describing the data mean [22].

The Semantic Web offers new technologies to the developers of web based applications aiming at providing more intelligent access and management of the Web information and semantically richer modeling of the applications and their users. "Expressing meaning" is the main task of the Semantic Web. Semantic Web is not the separate web but it is the extension of the current web which makes possible information to share and reuse. Semantic Web Technology (SWT) provides such environment, so that machines can talk with each other to fulfill the needs of the user by providing the right information. To accomplish this task, SWT uses a number of techniques like Ontology, RDFs, XML and SPARQL.

\section{The Semantic Web Architecture}

"Expressing meaning" is the main task of the Semantic Web. In order to achieve that objective, several layers of representational structures are needed. They are illustrated in Figure 2 (Berners-Lee 2000), among which the following layers are the basic ones [23]:

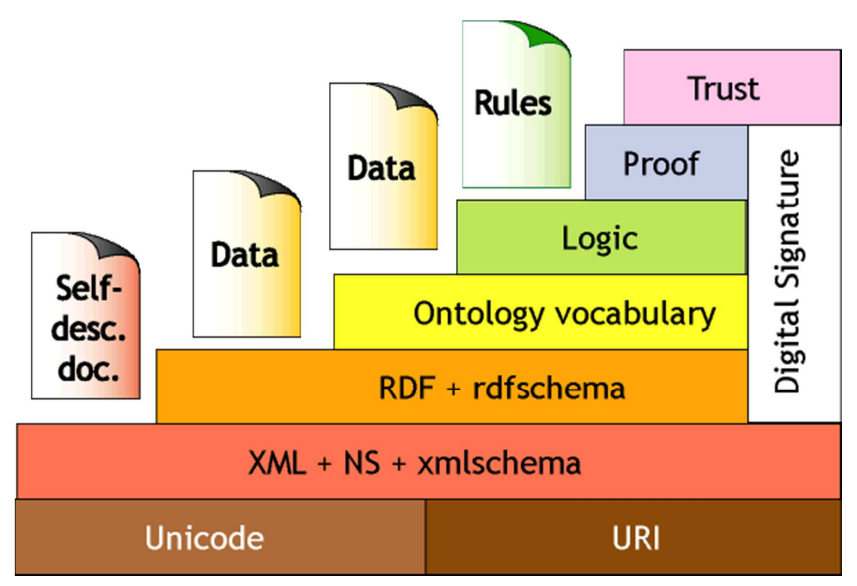

Figure 2. Layers of the Semantic Web architecture.

The term "Semantic Web" encompasses efforts to build a new WWW architecture that enhances content with formal semantics, means the content is made suitable for machine only, as opposed to content that is only intended for human. This will enable automated agents to reason about Web content, and produce an intelligent response to unexpected situations. "Expressing meaning" is the main task of the Semantic Web. In order to achieve that objective several layers of representational structures are needed [24].

The architecture can be divided into three parts which are [25]:

1. Knowledge representation (XML, XML schema and RDF, RDF schema layers).

2. Ontology (Ontology vocabulary layer).

3. Agents (Logic, Proof, Trust layers).

The important property of the Semantic Web architecture (i.e., common-shared-meaning and machine processable metadata), enabled by a set of suitable agents, establishes a powerful approach to satisfy the E-Learning requirements.

The process is based on semantic querying and navigation through learning materials, enabled by the ontological background. The Semantic Web can be exploited as a very suitable platform for implementing an E-learning system, because it provides all means for E-learning: ontology development, ontology-based annotation of learning materials, their composition in learning courses and active delivery of the learning materials through E-learning portals [26].

Tim Berners-Lee proposed four versions of Semantic Web architecture [27]. Such versions describe the languages needed for data interoperability between applications in the form of layering architecture, where each layer represents a 
language that provides services to the upper layer. However, layers described in such versions suffer from several deficiencies such as poor abstraction and rarely functional descriptions. Gerber in [28] avoided those deficiencies and designed a new architecture.

Additional layer called "Rules" layer was added although its functionality is already embedded inside other layers. The authors in [29] explored many layers compared to the Gerber's model. However, the overlapped functionalities among layers are more than overlapping in the Gerber's model and this increases the difficulty of the system engineering description and the layers integration. [30].

These versions describe the languages needed for data interoperability between applications in the form of layering architecture where each layer represents a language that provides services to the upper layer. The four versions (layered architectures) are composed mainly of seven functions. Each function is nearly represented by a layer. As we are talking about architecture concept, then there are some discrepancies and irregularities in Tim Berners-Lee's architectures considering the layered architecture evaluation criteria [31]. The layered architecture evaluation criteria are clearly defined context, an appropriate level of abstraction, hiding of unnecessary implementation details, clearly defined functional layers, appropriate layering, and Modularity. These criteria are used as an evaluation for any layering architecture.

The Semantic Web consists mainly of three components: the Extensible Markup Language (XML), the Resource Description Framework (RDF), and the ontologies.

Figure 2 shows the 9 layers architecture of semantic web in which the lowest layer starts from the bottom of the layer, followed by the highest layer, which is at the topmost position. The various layers and its challenges are described below.

\section{UNICODE}

Unicode is the basic universal number for every character, which works in multiple platforms. It is the basic notation, which is supported by top multinational companies like Motorola, IBM, Intel, etc. Unicode allows a single software, text or single character to be transported to other parts without corruption and re-engineering.

\section{URI (Uniform Resource Identifier)}

The URI is termed as Uniform Resource Identifier, which is a basic syntax for strings that is used to identify a resource. URI is the generic term of addresses and names of objects or resources in the WWW. A resource is any physical or abstract things in which each item has an identifier. The URI consists of two types: First is Uniform Resource locators (URL) which identifies a resource and how it can be accessed, and the second part is Uniform Resource Names (URN)that is used to create a universal and persistent name about a resource in its namespace. This namespace dictates the syntax of URN identifier [26].

It is used to identify resources on the web, in which every resource in the World Wide Web should be uniquely identified so we give it a URI. Resources could be anything such as a book, document, or video. There are different forms of the URIs. The most familiar form is the URL (Uniform Resource
Locator) which is typed in the Web browser to locate its corresponding resource, so it has two functionalities which are identifying and locating the resources. There are other forms that only identify the resources but can't tell us their locations. Because the Web is too large to be controlled by only one person or organization [32], so creation of URIs is decentralized and anyone could create URI for his resources. It is clear that a problem of identifying the same resource with more than one URI may exist, but it is the cost of having such flexible and simple technique to identify resources on the Web [33].

\section{XML (Extensible Mark-up Language)}

The Extensible Markup Language (XML) is a W3C-recommended general-purpose markup language that supports a wide variety of applications. XML is also designed to be reasonably human-legible, and to this end, terseness is not considered essential in its structure [32]. XML is evolved from simplified subset of Standard Generalized Markup Language (SGML). Its main task is to facilitate the sharing of data across different information systems, particularly systems connected via the Internet. XML is the simplest way to send the document across the web to its specific format. It allows users to edit or modify it and again transfer it. These document formats can include mark up also to enhance the meaning of the document [34]. Scientifically, XML is built upon Unicode characters and URI's. The Unicode characters allow XML to be characterized using International characters [26], [35].

XML Schema

XML Schema is a document definition language that enables you to develop XML documents into a Specific vocabulary and a specific hierarchical structure. The things you want to define in your language are element types, attribute types, and the composition of both into composite types (called complex types). XML Schema is different to database schema, which defines the column names and data types in database tables. XML Schema has been approved by W3C consortium in the year 2001. XMLS allows the validation of instances to ensure the accuracy of field values and document structure at the time of creation. The accuracy of fields is checked against the type of the field; for example, a quantity typed as an integer or money typed as a decimal. The structure of a document is checked for things like legal element and attributes names, correct number of children, and required attributes. All XML documents should be checked for validity before they are transferred to another partner or system [26]. There are different types of XML Schema Languages [34]: Document Definition Markup Language (DDML), Document Schema Definition Languages (DSDL), Document Structure Description (DSD), Document Type Definition (DTD), Namespace Routing Language (NRL), RELAX NG and its predecessors RELAX and TREXSGML Schema for Object-Oriented XML (SOX), Schematron XML-Data Reduced (XDR), XML Schema (W3C) (WXS or $\mathrm{XSD})$.

\section{XML Namespaces}

An XML namespace is the $\mathrm{W} 3 \mathrm{C}$ recommendation for providing uniquely named elements and all of its attributes in 
an XML instance. An instance of an XML contains element or attribute names from more than one vocabulary. If each vocabulary is given a namespace, then the uncertainty or what is unexpected between identically named elements or attributes can be resolved. All elements which are within a namespace must be in unique component [36].

\section{$R D F$ and $R D F$ Schema}

Resource Description Framework (RDF) is a foundation of metadata processing. It provides interoperability between applications that exchange machine-understandable information on the Web. It defines the relationship between the resources on the web. There are different syntaxes that can represent the RDF, one of the most popular syntax is the XML where the RDF based on this syntax is called RDF/XML model.

The RDF statement is written in a triple form consisting of three parts which are the subject, the predicate and the object, so it seems like it is a natural phrase but its parts are URIs as they are resources on the Web.

RDF defines a simple, yet powerful model for describing resources. A syntax (which is XML) representing this model is required to store instances of this model into machine-readable files and to communicate these instances among applications. RDF imposes formal structure on XML to support the consistent representation of semantics [37], [38].

The RDF and RDF Schema layer is located above the XML layer, which provides more functions and capabilities than in XML and XML schema. The Resource Description Framework is an XML based language that is used to describe resources. Such a resource is identified via a uniform resource locator (URL). As compared to XML documents that attach the metadata of the document, RDF captures the metadata of the externals of the document such as author, creation, date, etc.

$\mathrm{RDF}$ is the machine processable language, unlike XML which is human process able and it is not understandable by humans i.e. it knows what the machine is doing in the way it does. So that it can store smart information back on the Web. [39].

RDF model is also called as triple, because it contains three parts viz. Subject, Predicate and Object. In Subject, there is none of phrase that is the source of action. In Predicate, which is a part of triple edit the subject and includes the verb phrase? And in the object, it is a noun phrase that is the source of action by the verb.

RDFS or RDF Schema is a knowledge representation language, providing basic elements for the description of ontologies [40], otherwise called RDF vocabularies, intended to structure RDF resources. The data model of RDF schema allows creating classes of data. A class is defined as group of things with common characteristics. An object in the RDF schema is the instance of the class.

\section{Ontology Vocabulary}

The term "ontology" can be defined as an explicit specification of conceptualization [41], [42]. The conceptualization means modeling certain domain and the
Ontology is used to describe important concepts of this domain, so it is the specification of this conceptualization. Ontology is the stage where the vocabularies related to a specific domain should be defined. It provides the capability to make analysis on the relationships between the vocabularies to discover problems such as the existence of two vocabularies of the same meaning. In this stage, the relationships between vocabularies of a specific domain are created in hierarchal form by using the inheritance and classes concepts.

Languages such as OWL (Web Ontology Language) which may be considered as a syntactic extension for RDF/RDFS, are provided at this stage. The main layer of semantic web architecture is Ontology vocabulary, which typically consists of hierarchical distribution of important concepts in a domain, along with descriptions of the properties of each concept.

Ontologies play a pivotal role in the semantic web by providing a source of shared and precisely defined terms that can be used in metadata.

OWL (Web Ontology Language): OWL is intended to be used when the information contained in documents needs to be processed by applications, as opposed to situations where the content only needs to be presented to humans. OWL can be used to explicitly represent the meaning of terms in vocabularies and the relationships between those terms. This representation of terms and their interrelationships is called ontology. OWL has more facilities for expressing meaning and semantics than XML, RDF, and RDF-S, and thus OWL goes beyond these languages in its ability to represent machine interpretable content on the Web. The OWL has been designed to meet the requirements of RDF, RDFS, XML Schema [43].

Logic Layer

The logic layer in the semantic web is the universal language of monotonic logic. In the logic layer of semantic web architecture, any rule can export the code but cannot import it. Any system in the logic layer can validate proofs. This layer functions on the basic principle of first order predicate logic, so the information is displayed accurately on the web. [44].

Proof

In this layer, the ultimate goal of semantic web is to create a much smarter content which could be understood by the machines. When the content is understood by machine, some assertions may come out of the content and new pieces of information are produced. Unfortunately, this layer has not been investigated enough, this lack of investigation is not yet sufficiently considered to be a crucial problem.

Trust

This is the top most layer of the semantic web architecture, in which the trustworthiness of information should be subjectively evaluated by each information consumers. The trust does not exclude information providers which have not been rated or do not publish trust relevant information in a specific way. The trust layer in semantic web architecture is analyzed into four parts: The Information integration layer handles aggregation of information from different sources and adds provenance metadata in the information. The Repository 
Layer stores the aggregate information. The Query and Trust evaluation layer handles the actual trust decisions using query specific trust policies. The Application and explanation layer on which the retrieved information is used which an application context provides functionality to browse through explanations why data should be trusted.

\section{Digital Signature}

Digital signatures run horizontal to the RDF family up through the proof layer and support the notion of trust. Developments in the area of digital signatures are progressing, and could eventually help validate the integrity of metadata that an agent is using for reasoning and task completion. The main purpose of the digital signature is to digitally sign the document. Also encryption methods are used to run on digital signed documents to prevent against unauthorized access.

The semantic Web architectures show the main functionalities that should be provided to achieve the desired goals of the semantic Web. Each of these functionalities is associated with one of the layers of layered cake architecture of the semantic Web. Each function may be realized in several ways using any of the suitable available technologies.

\section{Results and Benefits of Using Semantic Web}

\section{Limitation of current e-learning environments}

E-Learning (Electronic-Learning) is just learning using technologies like computer system, internet, and network [45]. Current e-learning environments are developed in computer programming languages. It works according to how it is programmed well in advance. Sometimes it fails to supply learning resources according to the learner's needs, and produce irrelevant results which do not match the learner's query and interest. So that learner has to be involved and should spend time to categorize the web results, which he/she actually requires to learn [46].

The Semantic Web is used as a backbone for e-learning. Foremost, the objectives are to ease the contribution of and the efficient access to the information. But, in general, a Semantic Web-based learning process could be a personalized (user customized), relevant (problem-dependent), and an active (context-sensitive) [47].

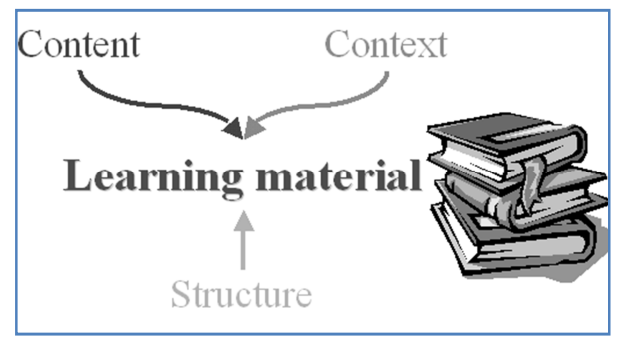

Figure 3. Learning Material Dimension.

From the student point of view, the most important criterions for searching learning materials are: what the learning material is about (content) and in which form this topic is presented (context). However, while learning material does not appear in isolation, another dimension (structure) is needed to encompass a set of learning materials in a learning course as shown in figure 3.

Learning object and courses databases are syntactically structured text archives with powerful search engines. But, search engines for Learning objects information retrieval do not include knowledge into their search strategies. These strategies include keyword and metadata search, but do not address the semantics of the keywords, which would allow, for instance, conceptual query expansion. In other words, there is no semantic relationship between information needs of the user and the information content of documents [48] [49].

Nowadays, e-learning systems are widely used for education and training in universities and companies because of their electronic course content access and virtual classroom participation. However, with the rapid increase of learning content on the Web, it is time-consuming for learners to find contents they really want to and need to study.

The e-learning material (course) may be decomposed into Learning Objects (LOs). The LOs may be considered as basic units (modules) of the e-learning material satisfying certain requirements. This mechanism enables reusability, in which the same LOs may be used to build different courses.

Decomposing the e-learning material into LOs and knowing the relationships between these learning objects is one of the main problems that face this approach. Improving the creation of the relationships between the LOs in an efficient way needs understanding of the context and the semantics of the learning objects. This is one of the main functionalities and roles of the semantic Web since the Semantic Web is an efficient mechanism to represent the semantics of the resources. It aims at providing a promising foundation for enriching resources, with well defined meanings.

If an e-learner needs to know about a specific course, then he/she may search using specific related keywords. The result of the search may include irrelevant data with respect to his/her preferences. One of the best approaches to overcome this issue is to use ontology for the e-learner. This e-learner ontology defines concepts about the e-learner and relationships between the concepts. It enables us to describe an e-learner profile that semantically relates the appropriate and relevant learning objects to the e-learner.

Retrieving information effectively on the Web is becoming a harder problem. Most current search engines are keyword based, so the retrieved documents match these submitted keywords. In traditional search, not all retrieved documents are relevant. Approximately one half is irrelevant regardless the user model; the same keywords always return the same documents. The users may not have similar interests, background, preferences, and goals, so the same keyword may have different meanings to different users. Personalized or customized retrieved document list is more helpful since it is more relevant. A user model is needed to allow customized responses to the user according to his/her model. 
The semantic Web overcomes this limitation where structured meaning and annotation is attached to the navigational data of the current Web.

Semantic Web Technology (SWT) helps the learners for better e-learning by providing the most significant learning materials, which suit the individuals, like learner's profile, needs and interest [45]. Semantic Web solves the limitation of current e-learning environment by providing most relevant learning resources to an e-learner quickly.

In Table 3, a summary view of the possibility to use the Semantic Web, for realizing the e-Learning requirements, is presented.

Table 3. Benefits of using Semantic Web as a technology for E-Learning.

\begin{tabular}{|c|c|c|}
\hline Requirements & E-Learning & Semantic Web \\
\hline Delivery & Pull-Student determines agenda & $\begin{array}{l}\text { Knowledge items (learning materials) are distributed on the web, But they are linked to } \\
\text { commonly agreed ontologie(s). This enables construction of a user-specific course, by } \\
\text { semantic querying for Topics of interest. }\end{array}$ \\
\hline Responsiveness & Reactionary - Responds to problem at hand & $\begin{array}{l}\text { Software agents on the Semantic Web may use a commonly agreed service language, } \\
\text { which enables co-ordination between agents and proactive delivery of learning } \\
\text { materials in the context of actual problems. The vision is that each user has his own } \\
\text { personalized agent that Communicates with other agents. }\end{array}$ \\
\hline Access & $\begin{array}{l}\text { Non-linear - Allows direct access to } \\
\text { knowledge in whatever sequence makes } \\
\text { sense to the situation at hand }\end{array}$ & $\begin{array}{l}\text { User can describe the situation at hand (goal of learning, previous knowledge,...) and } \\
\text { perform semantic querying for the suitable Learning material. The user profile is also } \\
\text { accounted for. Access to Knowledge can be expanded by semantically defined navigation. }\end{array}$ \\
\hline Symmetry & $\begin{array}{l}\text { Symmetric - Learning occurs as an } \\
\text { integrated activity }\end{array}$ & $\begin{array}{l}\text { The Semantic Web (semantic intranet) offers the potential to become an integration } \\
\text { platform for all business processes in an Organization, including learning activities. }\end{array}$ \\
\hline Modality & $\begin{array}{l}\text { Continuous - Learning runs in parallel to } \\
\text { business tasks and never stops }\end{array}$ & $\begin{array}{l}\text { Active delivery of information (based on personalized agents) creates a dynamic } \\
\text { learning environment that is integrated in the Business processes. }\end{array}$ \\
\hline Authority & $\begin{array}{l}\text { Distributed - Content comes from the } \\
\text { interaction of the participants and the } \\
\text { educators }\end{array}$ & $\begin{array}{l}\text { The Semantic Web will be as decentralized as possible. This Enables an effective } \\
\text { co-operative content management. }\end{array}$ \\
\hline Personalization & $\begin{array}{l}\text { Personalized - Content is determined by the } \\
\text { individual user's needs and aims to satisfy } \\
\text { the needs of every user }\end{array}$ & $\begin{array}{l}\text { A user (using its personalized agent) searches for learning material Customized for her/his } \\
\text { needs. The ontology is the link between User needs and characteristics of the learning } \\
\text { material. }\end{array}$ \\
\hline Adaptively & $\begin{array}{l}\text { Dynamic - Content changes constantly } \\
\text { through user input, experiences, new } \\
\text { practices, business rules and heuristics }\end{array}$ & $\begin{array}{l}\text { The Semantic Web enables the use of distributed knowledge provided in various forms, } \\
\text { enabled by semantically annotation of Content. Distributed nature of the Semantic } \\
\text { Web enables Continuousimprovement of learning materials. }\end{array}$ \\
\hline
\end{tabular}

\section{Conclusions}

The real value of e-Learning lies not in its ability to train just anyone, anytime, anywhere, but in our ability to deploy this attribute to train the right people to gain the right skills or knowledge, at the right time. This process reduces the cost of learning and adds a degree of freedom that enables the e-learner to control the activities and the courses that he/she is interested in.

Semantic Web Technology (SWT) in which information in machine-processable form, can coexist and complement the current web with better enabling computers and people to work in co-operation. Making the content machine-understandable is a popular paraphrase of the fundamental prerequisite for the semantic web. With the rapid increase of learning content on the Web, it will be time-consuming for learners to find contents they really want to and need to study. The Semantic Web Technology (SWT) has the potentiality to be applied in different areas.

E-Learning is one of the domains which may benefit from this new web technology. Semantic Web Technology helps to learners for better E-learning by providing the most significant learning materials, which suit to the individual like learner's profile, needs and interest.
This paper focuses on potential uses of Semantic Web Technology (SWT) in E-Learning, as well as advantages of using Ontology to describe learning materials. It is a great platform to represent the E-learning management system that recovers the limitations of Web 2.0.

In this paper, the limitations of the conventional Web and how the Semantic Web overcomes those limitations have been discussed. Then, the common technologies used to construct the E-learning and Semantic Web is presented.

The architecture of the Semantic Web is discussed, which introduces the essential components of the Semantic Web, such as eXtensible Mark-up language (XML), XML scheme, Resource Description Framework (RDF), RDF scheme, and Web Ontology language (OWL).

The purpose of this paper is to clarify possibilities of using the Semantic Web as a backbone for E-Learning, which provides flexible and personalized access to these learning materials.

\section{References}

[1] T. Govindasamy, "Successful implementation of e-Learning Pedagogical considerations," Internet and Higher Education, vol. 4, p. 287-299, 2002. 
[2] K. S. Neepa, "E-Learning and Semantic Web," International Journal of e-Education, e-Business, e-Management and e-Learning, vol. 2, no. 2, April 2012.

[3] J. Hendler, "Agents and the Semantic Web," IEEE Intelligent Systems, vol. 16, no. 2, pp. 30-37, 2001.

[4] G. Fayed, D. Sameh, H. Ahmad, M. A. Jihad, A. E.-S. Samir and E.-S. Hosam, "E-Learning Model Based On Semantic Web Technology," International Journal of Computing \& Information Sciences, vol. 4, no. 2, pp. 63 -71, 2006.

[5] B. Dutta, "Semantic Web Based E-learning," [Online]. Available:

https://www.researchgate.net/publication/242691487_Semanti c_Web_Based_E-learning.

[6] N. Kontodimopoulos, A. BOUKOUVALAS1, K. Savidakis and A. Gasparinatou, "Distance-Learning Educational Material in the Biomedical Engineering Degree Program," in WSEAS Int Conf. on ENGINEERING EDUCATION, Venice, Italy, 2004.

[7] Hoppe, G.; Breitner, M. H, "Business Models for E-Learning," in E-learning,models, istrument,experiences, of the Multikonferenz Wirtschaftsinformatik, Essen-Germany, 2004.

[8] G. Jorge, M. Ruiz and J. Michael, "The Impact of E-Learning in Medical Education," in Academic Medicine, 2006.

[9] "e-Learning- Introductions," [Online]. Available: $\mathrm{http} / / /$ agelesslearner.com/intros/elearning.html.

[10] P. Drucker, "Need to Know Integrating e-Learning with High Velocity Value Chains," A Delphi Group White, 2000

[11] L. Stojanovic, S. Steffen and S. Rudi, "eLearning based on the Semantic Web," in WebNet'2001 World Conference of the WWW and Internet. AACE (2001), 2001.

[12] Y. Zhiwen, N. Yuichi, J. Seiie and K. Shoji, "Ontology-Based Semantic Recommendation for Context-Aware E-Learning," in Ubiquitous Intelligence and Computing, Springer Berlin Heidelberg, 2007, pp. pp 898-907.

[13] T. Dietinger, "ASPECTS OF E-LEARNING ENVIRONMENTS," Graz University of Technology, 2003.

[14] A. Rossett, THE ASTD E-LEARNING HANDBOOK BEST PRACTICES, STRATEGIES, AND CASE STUDIES FOR AN EMERGING FIELD, New York: McGraw-Hill, 2002.

[15] M. R. Charles and A. C.-C. Alison, Instructional-Design Theories and Models, New York: Taylor \& Francis publishing, 2009.

[16] M. Elazony, "master's thesis"Presentation Techniques for Distance Learning"," cairo, 2011.

[17] J. Hofmann, "Blended Learning Case Study," 2001. [Online]. Available: http://www.astd.org/LC/2001/0401 hofmann.htm. [Accessed 13 January 2009].

[18] B. Karin, C. M. Antonio and T. Walt, Semantic Web: Concepts, Technologies and Applications, Springer Science \& Business Media, 2007.

[19] T. Berners-Lee, J. Hendler and O. Lassila, "The Semantic Web: A new form of Web content that ismeaningful to computers will unleash a revolution of new possibilities.," Scientific American., 2001.

[20] "Semantic_Web," 2013. [Online]. Available: http://en.wikipedia.org/wiki/Semantic_Web. [Accessed 2013].
[21] B. Ö. Czerkawski, "THE SEMANTIC WEB IN TEACHER EDUCATION," TOJET: The Turkish Online Journal of Educational Technology, vol. 13, no. 4, October 2014.

[22] V. Devedžić, "Web Intelligence and Artificial Intelligence in Education," Web Intelligence and Artificial Intelligence in Education. Educational Technology \& Society, vol. 4, no. 7, pp. 29-39, 2004.

[23] T. Berners-Lee, "What the Semantic Web can represent," 1709 1998. [Online]. Available: http://www.w3.org/DesignIssues/RDFnot.html. [Accessed 31 03 2013].

[24] T. Berners-Lee, "Semantic Web Road map," 1998. [Online]. Available: http://www.w3.org/DesignIssues/Semantic.html..

[25] M.-B. T, Everything Integrated: A Framework for Associative Writing in the Web, University of Southampton, 2004.

[26] L. O. K. T. S. Michael Daconta, The Semantic web: the guide to future of XML,web services and knowledge management.

[27] A. B. A. J. v. d. M. A. Gerber, "Functional Semantic Web Architecture,"," Springer Berlin / Heidelberg, Lecture Notes in Computer Science, Vols. Volume 5021/2008, ISBN:978-3-540-68233-2, pp. pages: 273-287, 2008.

[28] A. B. A. J. v. d. M. A. Gerber, "Towards a Semantic Web Layered Architecture," in Software Engineering Proceedings of the 25th conference on IASTED International Multi-Conference, Innsbruck, Austria,, 2007.

[29] M. A. a. H. S. H. Al-Feel, "Toward an Agreement on Semantic Web Architecture," in World Academy of Science,Engineering and Technology, 2009.

[30] H. Pascal and J. Krzysztof, "Semantic Web Tools and Systems," Semantic Web, vol. 2, no. 1/2011, 2011.

[31] B. P. P. P.-S. J. I. Horrocks, "Semantic Web Architecture: Stack or Two Towers?" "Lecture Notes in Computer Science, Vols. Volume 3703/2005,, no. ISBN: 978-3-540-, pp. Pages: 37-41, 2005.

[32] A. Swartz, "The Semantic Web in Breadth," 2002. [Online]. Available: http://logicerror.com/semanticWeb-long..

[33] R. Pandey and S. Dwivedi, "Interoperability between Semantic Web Layers: A Communicating Agent Approach," International Journal of Computer Applications, vol. 12, no. 3, p. $0975-8887$, November 2010.

[34] "XML_schema," [Online]. Available: http://en.wikipedia.org/wiki/XML_schema.

[35] T. Bray, "Extensible Markup Language (XML) 1.1 (Second Edition)," $2006 . \quad$ [Online]. Available: http://www.w3.org/TR/xml11/\#sec-origin-goals.

[36] "REC-xml-names," [Online]. Available: http://www.w3.org/TR/REC-xml-names.

[37] D. Beckett, "RDF/XML Syntax Specification (Revised)," 2004 [Online]. Available: http://www.w3.org/TR/REC-rdf-syntax/. [Accessed 2013].

[38] E. Miller, "An Introduction to the Resource Description Framework," D-Lib Magazine, 1998.

[39] "Resource Description Framework," [Online]. Available: http://en.wikipedia.org/wiki/Resource Description Framewor $\mathrm{k}$. 
[40] "rdf-schema," http://www.w3.org/TR/rdf-schema.

[41] M. Obitko., "Introduction to Ontologies and Semantic Web," 2007. [Online]. http://www.obitko.com/tutorials/ontologies-semantic-web/.

[42] S. S. A. Maedche, "Ontology Learning for the Semantic Web," IEEE Intelligent Systems, vol. 16, no. ISSN:1541-1672, pp. 729,2001 .

[43] "owl-features," [Online].

Available: http://www.w3.org/TR/owl-features.

[44] "Logic layer," [Online].

Available: http://www.w3.org/2002/Talks/04-sweb/slide20-0.html.

[45] S. K. Patel and B. H. B, "AUTOMATIC DISCOVERY AND PRESENTATION OF HIGHLY PERSONALIZED E-LEARNING RESOURCES: A SURVEY," International Journal of Advanced Technology \& Engineering Research (IJATER), vol. 3, p. 25-29, 2013.
[46] L. T and R. S, "Information Portal of E-Learning System in Semantic Web Environment," in The 6th IEEE International Conference on Intelligent Data Acquisition and Advanced Computing Systems: Technology and Applications, 2011.

[47] L. Stojanovic, S. Staab and R. Studer, "eLearning based on the Semantic Web," in WebNet'2001 World Conference of the WWW and Internet. AACE (2001), 2001.

[48] M. Frank and E. Miller, "RDF Primer:W3C Recommendation 10 February 2004," W3C, 10 February 2004. [Online]. Available: http://www.w3.org/TR/2004/REC-rdf-primer-20040210/. [Accessed 108 2015].

[49] M. Frank, M. Eric and M. Brian, "RDF 1.1 Primer:W3C Working Group Note 24 June 2014," W3C, 24 June 2014. [Online]. Available: http://www.w3.org/TR/2014/NOTE-rdf11-primer-20140624/. [Accessed 108 2015]. 